\title{
APRESENTAÇÃO
}

\section{As vias qualitativas da indagação social}

Angélica de Sena'

Lorena Almeida Gill

As Ciências Sociais são parte de um conjunto de conhecimentos e procedimentos que os seres humanos têm inventado para melhorar o nosso mundo, com a ajuda dos agentes sociais, que são os que "sabem na verdade o que é o mundo". Para todas as estratégias de indagação e, em especial, na perspectiva qualitativa sobre os processos e interações de conhecer o mundo social, devem-se aplicar as palavras de um dos pais fundadores das ciências sociais, como foi Florestan Fernandes:

\begin{abstract}
Como lembra Madge, um pesquisador social sem treino adequado pode ver muito, mas identificar pouco; enquanto um pesquisador social com ideias rigidas acaba vendo apenas os fatos que confirmam suas concepções. Além disso, é preciso não negligenciar o papel da análise como recurso de observação nas ciências sociais (FERNANDES, 1997, p. 48).
\end{abstract}

É evidente que uma indagação sem um olhar teórico conduz à miopia e uma pesquisa que seja uma mera reprodução do real conduz à autoconfirmação tranquilizadora. As metodologias qualitativas têm sido cada vez mais utilizadas em diferentes áreas do conhecimento como Sociologia, História, Educação, Antropologia, Comunicação, dentre outras. O seu uso tem se associado a algumas tradições teóricas, epistemológicas e metodológicas, que no decorrer dos anos se consolidaram e abriram o caminho a discussões e modos de indagar mais amplos.

A pesquisa qualitativa do modo tramado, nesta edição da revista Novos Rumos Sociológicos (Norus), deve nos fazer pensar em ciências sociais que estejam atentas para não incorrer nem em falácias epistêmicas nem na consagração do que é tido como dado.

\footnotetext{
1 Professora na Universidad Nacional de La Matanza (UNLaM)e na Universidad de Buenos Aires (UBA). Pesquisadora na UNLaM, no Instituto Gino Germani da Facultad de Ciencias Sociales (UBA) e no Centro de Investigaciones y Estudios Sociológicos (CIES), na Argentina.

2 Professora do Programa de Pós-Graduação em Sociologia e do Programa de Pós-Graduação em História da Universidade Federal de Pelotas.
} 
No campo da prática das ciências sociais e humanas, conectar-se com o qualitativo não é um fenômeno novo. Na sociologia, particularmente na escola de Chicago, a importância do qualitativo como estratégia de reconstrução do olhar dos sujeitos têm desempenhado um papel central na compreensão da realidade. Infelizmente, o "auge" da pesquisa qualitativa tem sido, muitas vezes, compreendido e reduzido a uma forma de "resposta" às abordagens quantitativas de uma sociologia positivista, e este não é o caso em um sentido epistêmico "forte".

Um dos equívocos mais comuns entre pesquisadores recém-iniciados, em relação à pesquisa qualitativa, é a associação unívoca e absoluta das técnicas qualitativas com as estratégias metodológicas qualitativas. Essa confusão traz consigo muitos problemas de desenho para a pesquisa, de volume e importância semelhantes aos encontrados na realização de uma enquete, acreditando que na aplicação do instrumento se encerra o estudo quantitativo da sociedade. A isto pode-se acrescentar a existência de um preconceito teórico muito naturalizado sobre as diferenças entre estratégias quantitativas e qualitativas, tomadas como paradigmas rivais e incomensuráveis.

Nas ciências sociais do século XXI, felizmente se entende e aceita-se que as estratégias qualitativas de indagação não se reduzem a uma "resposta" aos enfoques positivistas; estão fortemente relacionadas às escolhas teóricas que são feitas; implicam um conjunto de procedimentos, pressupostos e regras que vão além da mera aplicação de técnicas; e a complementaridade constituída entre o olhar quantitativo e qualitativo.

Dessa forma, este número da revista Novos Rumos Sociológicos (Norus) apresenta textos que dialogam com metodologias qualitativas, a partir de construção de narrativas, as quais envolveram, especialmente, entrevistas, em suas diferentes possibilidades. 
O primeiro artigo, intitulado "História Oral: reflexões sobre aplicações e implicações", de autoria de Samantha Castelo Branco traz o debate sobre a metodologia de História oral, a partir de questões técnicas e éticas que envolvem o procedimento.

O segundo texto "Memoria y Testimonios: uso de testimonios orales en los Museos de la Memoria del Cono Sur Americano", de Ana María Sosa González, se preocupa em analisar testemunhos, relacionados à história do tempo presente, que envolvem processos traumáticos e se vinculam a museus. A autora observa que o uso de testemunhos na expografia, dessas instituições, tem sido a cada dia mais frequente, criando uma maior sensibilização e conscientização sobre os processos de conformação da memória.

O terceiro artigo "Miradas sobre la alteridade: Entrevistas semiestructuradas a policias en torno a los vínculos entre inmigración y delincuencia" de Federico Luis Abiuso examina, a partir de entrevistas semiestruturadas, numa pesquisa localizada na cidade de Buenos Aires, as visões que policiais e funcionários do poder judiciário constroem sobre um nexo entre a imigração e a delinquência.

Continuamos com o quarto artigo de María Micaela Bazzano, cujo título é "Reflexiones metodológicas en torno a la aplicación conjunta de la etnografia virtual y la entrevista en profundidad para el estudio de las emociones" e que apresenta, a partir de uma tese de Doutorado, como usar duas técnicas diversas e sua complementaridade para se pensar as emoções.

$\mathrm{O}$ quinto texto intitulado "A teoria das representações sociais como instrumento de compreensão da realidade: Aproximações à luz da experiência concreta" de autoria de Flávio Sacco dos Anjos, reflete sobre a importância heurística dessa metodologia para o campo das ciências sociais, especialmente no que se refere ao estudo do rural.

Por fim, encerramos a série de artigos com uma tradução. O texto intitulado "A entrevista: um olhar sobre a escuta a partir de duas 
experiências" de Adrian Scribano e Angelica de Sena, centra a análise nas potencialidades da entrevista para explicar reflexivamente a estruturação social.

Trata-se, portanto, de textos com diferentes olhares sobre as metodologias qualitativas. Não queremos terminar estas linhas sem fazer alusão à presença do olhar de todos $\mathrm{e}$ todas na pesquisa $\mathrm{e}$ no desenvolvimento científico:

\begin{abstract}
A metodologia é uma das principais ferramentas - e não menos importante - para parar de emprestar gargantas a outras vozes, para gerar curto-circuito na reprodutibilidade ingênua da teoria, para dar potência às capacidades negadas, invalidadas e obturadas, quando a construção do conhecimento se apresenta como tarefa de uns poucos privilegiados (SCRIBANO, et al,. 2007, p. 12).
\end{abstract}

É nesse contexto que celebramos a publicação deste número, onde é possivel observar o quanto desenvolvemos o qualitativo e o quanto ainda nos resta por fazer. Desejamos a todas e todos uma boa leitura!

\title{
Referências
}

FERNANDES, Florestan. A Reconstrução Da Realidade Nas Ciências Sociais. Rev. Mediações, Londrina v. 2. n. 1, P 47 56, jan./jun. 19, (1957), 1997.

SCRIBANO, Adrián, GANDÍA, C. Magallanes, G. y Vergara G. Metodologia de la investigación social. Una indagación sobre las prácticas del enseñar y aprender. Universidad Nacional de Villa María. Buena Vista Editores. Córdoba, 2007. 